\title{
Heterogeneous Consumers in the Monopolistically Competitive Setting
}

\author{
Alexander Osharin \\ National Research University Higher School of Economics, Nizhny Novgorod, Russia \\ *Corresponding Author: aosharin@hse.ru
}

Copyright (C) 2013 Horizon Research Publishing All rights reserved.

\begin{abstract}
The paper investigates distributional effects and market structure in a one-sector model of monopolistic competition with heterogeneous consumers. By using the CES utility function depending on consumer's personal income the paper shows how the equilibrium prices, firm size and number of firms depend upon income distribution and intensity of competition. The proposed model extends the traditional Dixit-Stiglitz approach and has a wider range of applications.
\end{abstract}

Keywords Monopolistic Competition, Heterogeneous Consumers, Income Distribution

\section{Introduction}

The question of consumer's preferences impact on market structure and international trade is one of the urgent and widely discussed in the contemporary literature. Its importance can be attributed to both the success of theoretical analysis and accumulation of the empirical facts, which cannot be satisfactorily explained by the traditional models. Currently in the most of the models the demand side of an economy is analyzed using rather crude approximation. It is typically assumed that consumers have identical and homothetic preferences within and across countries [1-3]. As a consequence, an aggregate demand is supposed to depend only upon commodity prices and aggregate income and doesn't depend on the income distribution. Such assumptions are used due to analytical convenience and tractability. They sufficiently simplify calculations, but have a lot of shortcomings, empirically implausible, and vigorously discussed in the literature [4-6].

In the meantime, though, there is an increasing list of publications where an attempt is made to take the heterogeneity and non-homotheticity of consumers' preferences into account when explaining market structure and international trade effects [7-13].

The present paper continues this line of research by providing a one-sector model of monopolistic competition with heterogeneous consumers and firms. By using the CES utility function depending on consumer's personal income, the paper derives the individual and market demand functions and investigates distributional effects and market structure in the monopolistically competitive setting.

The key difference between the present and most of the traditional models regards the difference between the individual and collective choice description. An assumption of identity of the consumers' preferences, used in the most of the models, makes it impossible to discriminate between the individual and market demand and, consequently, between individual and collective consumers' behavior. This observation refers also to the production side of an economy. Any firm, making pricing decisions, faces and reacts on the market (not individual) demand curve. Nevertheless, to discriminate between the two, one needs to assume heterogeneity in consumer's preferences. In the present paper the heterogeneity of consumer's preferences is supposed to be due to personal income inequality.

\section{Model}

\subsection{Demand-side}

There is a one-sector economy, which population is divided into $K$ income groups; $L_{k}$ and $y_{k}$ are the number and income of individuals in the group $k(k=1,2, \ldots, K)$. The preferences of any individual in the group are given by a "modified" CES utility function:

$$
U_{k}=\left(\sum_{i=1}^{N} x_{k i}^{\left(\sigma_{k}-1\right) / \sigma_{k}}\right)^{\sigma_{k} /\left(\sigma_{k}-1\right)}
$$

where $x_{k i}$ is the quantity of variety $i$ consumed by an individual having income $y_{k}, N$ is the total number of varieties available, equal to the number of firms, each producing a different variety. Contrary to the Dixit-Stiglitz approach [1], the parameter $\sigma_{k}$ in (1) is not a constant identical for all consumers; it is supposed to be different for consumers having different personal incomes. This fact reflects heterogeneity of consumers' preferences and 
explains what is "modified" about CES utility function in the present paper.

Using "modified" CES utility function, each consumer solves the following optimizing procedure

$$
\left\{\begin{array}{l}
U_{k}=\left(\sum_{i=1}^{N} x_{k i}^{\left(\sigma_{k}-1\right) / \sigma_{k}}\right)^{\sigma_{k} /\left(\sigma_{k}-1\right)} \rightarrow \max _{k i} \\
\sum_{i=1}^{N} p_{k i} x_{k i}=y_{k}
\end{array}\right.
$$

and gets the individual demand functions

$$
x_{k i}=\frac{p_{k i}{ }^{-\sigma_{k}}}{\tilde{P}_{k}} y_{k}
$$

where $i=1,2, \ldots, N, k=1,2, \ldots, K, p_{k i}$ is the corresponding demand price, $\widetilde{P}_{k}=\sum p_{k j}^{-\left(\sigma \sigma_{k}-1\right)}$ is a price aggregate.

The individual demland functions are used then to derive the market demand functions for individual varieties:

$$
q_{i}=\sum_{k=1}^{K} \frac{L_{k} y_{k}}{P_{k}} p_{i}^{-\sigma_{k}}
$$

where $i=1,2, \ldots, N, P_{k}=\sum_{j=1}^{N} p_{j}^{-\left(\sigma_{k}-1\right)}$.

Recognizing the key parameter in our model to be a function $\sigma_{k}=\sigma\left(y_{k}\right)$, which determines price elasticities for individual and market demand curves, income elasticity coefficients, elasticities of substitution across varieties, etc. $[1,3,14]$, it's important to know its shape.

Since price elasticity for individual demand curves (up to the sign) equals $\sigma_{k}, \varepsilon_{k}=-\sigma_{k}[1,3,14]$, it is reasonable to choose the dependence of $\sigma_{k}$ upon income to fit the correspondent $\varepsilon_{k}$ income dependence. It should be noted that the problem of price elasticity $\varepsilon_{k}$ dependence upon consumer's income was discussed in the early days of the theory of imperfect competition and can be traced back to "The Economics of Imperfect Competition" [15], in which Joan Robinson wrote:

"An increase in wealth is likely to make the demand of the individual buyer of any particular commodity less elastic. Thus an increase in demand due to an increase of wealth is likely to reduce the elasticity of the demand curve, and may reduce the elasticity so much that the slope of the curve is increased."

Following the Robinson conjecture, the negative relation of $\sigma_{k}$ upon income $y_{k}$ is further assumed throughout the paper. Its explicit representation will be discussed in section 4.1 below.

\subsection{Supply-side}

Now turn to the supply-side of our model and consider the producer problem. Assume that firm technology is represented by a cost function exhibiting constant marginal $\operatorname{cost} c_{i}$, which is different for different firms, and a fixed overhead cost $f$, which is supposed to be the same across firms. In choosing the appropriate price level, each firm faces a market demand curve (4) and solves the following optimization procedure:

$$
\pi\left(p_{i}\right)=\left(p_{i}-c_{i}\right)\left(\sum_{k=1}^{K} \frac{L_{k} y_{k}}{P_{k}} p_{i}^{-\sigma_{k}}\right)-f \rightarrow \max _{p_{i}}
$$

where $i=1,2, \ldots, N$. This yields the sufficient conditions for profit maximization in the monopolistically competitive setting:

$$
\sum_{k=1}^{K} \frac{L_{k} y_{k}}{P_{k}}\left(\sigma_{k}-1\right) p_{i}^{-\sigma_{k}}-\frac{c_{i}}{p_{i}} \sum_{k=1}^{K} \frac{L_{k} y_{k}}{P_{k}} \sigma_{k} p_{i}^{-\sigma_{k}}=0
$$

where $i=1,2, \ldots, N$. These conditions differ drastically from those in Dixit and Stiglitz $[1,3,14]$ and represent a system of $N$ simultaneous nonlinear algebraic equations. To get the equilibrium price vector and its dependence upon exogenous parameters of the model, this system could be solved numerically.

\section{Partial Equilibrium for Identical Firms}

Assuming for simplicity all firms to be identical (i.e. putting $c_{i}=c$ for all $\left.i=1,2, \ldots, N\right)$ and searching for the symmetric equilibrium, an analytical solution of the system (6) can be obtained. It reduces to

$$
p^{*}=\frac{\widetilde{\sigma}}{\widetilde{\sigma}-1} c
$$

The key parameter, which determines the price level, is the "effective" sigma:

$$
\tilde{\sigma}=\frac{1}{\bar{y}} \sum_{k=1}^{K} \lambda_{k} y_{k} \sigma_{k}
$$

$\bar{y}$ is the average personal income of consumers, $\lambda_{k}=L_{k} / L$ is the income distribution (i.e. share of the consumers with income $y_{k}$, in the total number of consumers). Given functions $\sigma_{k}=\sigma\left(y_{k}\right)$ and $\lambda_{k}=\lambda\left(y_{k}\right)$, one can obtain $\widetilde{\sigma}$ and then find the values of all the endogenous parameters of the model. In the present paper the income distribution is defined exogenously, so the equilibrium described in the model can be considered as partial equilibrium.

Traditional definition of the mark-up over marginal cost $\mu^{*}=\left(p^{*}-c\right) / p^{*}$ yields equilibrium mark-up, which is inversely dependent upon the "effective" sigma: 


$$
\mu^{*}=\frac{1}{\widetilde{\sigma}}
$$

Given equilibrium price level, the zero profit condition $\pi^{*}=\left(p^{*}-c\right) q^{*}-f=0$ then provides an equilibrium firm size:

$$
q^{*}=\frac{(\tilde{\sigma}-1) f}{c} .
$$

Multiplying both sides of budget constraint in (2) by $L_{k}$ and summing up over all income groups of consumers, one can get the equilibrium number of firms:

$$
N^{*}=\frac{\bar{y} L}{\tilde{\sigma} f}
$$

Formally, expressions for the optimal price level, firm output and number of firms in heterogeneous case turn out to be quite similar to those in the Dixit-Stiglitz model $[1,3,14]$ and coincide with them in homogeneous case. Nevertheless, there is essential difference between the two models. In the heterogeneous case the parameters of the model depend on the income distribution of the consumers, while in the homogeneous case they don't. It makes it possible to study consumer's collective behavior effects due to income distribution transformation. Fixing the average income and changing income variance, one can find the aggregate price, mark-ups, output of a firm, and firm number dependence upon the level of inequality in the economy. In the homogeneous case, where all consumers are supposed to be identical (and collective behavior reduces to the behavior of an individual), the dependence of the aforementioned parameters upon income inequality is absent.

The outlined model can be easily extended to investigate the trade effects in the open economy case. Following the logic of the model one doesn't need to assume the income and preferences of consumers being identical in different countries. Such an extension allows one to get some new results concerning interrelations between consumer's preferences, market structure and trade patterns. The analysis could be carried out both on the basis of symmetric equilibrium with identical firms and in more general setting, where firms are supposed to differ in their marginal costs.

\section{Results}

\subsection{Distribution of Consumers' Income and Shape of the Sigma Function}

In order to illustrate how income inequality effects market demand pattern for any variety and, thereby, market outcomes (i.e. equilibrium price levels, mark-ups, firm size, number of firms etc.), assume the consumers' income distribution to be lognormal with density

$$
\lambda(y)=\frac{1}{y s \sqrt{2 \pi}} \exp \left[-\frac{(\ln y-m)^{2}}{2 s^{2}}\right]
$$

where $-\infty<m<+\infty, s>0$ are constant parameters ${ }^{1}$. Lognormal distribution is frequently used in the literature as an approximation of empirically observed income distributions $[16,17]$. Solving the model numerically, the parameters $m$ and $s$ in (12) are chosen so as to make the variance of the income distribution vary while keeping the average income of consumers $\bar{y}$ constant. In doing so, the Gini coefficient is used instead of variance as a standard measure of inequality. The Gini coefficient is known to vary between 0 and 1 , with its higher values corresponding to greater income inequality, and is calculated by

$$
\text { Gini }=1-\frac{1}{\bar{y}} \int_{0}^{+\infty}(1-\Lambda(y))^{2} d y
$$

where $\Lambda(y)$ is the cumulative distribution function for (12):

$$
\Lambda(y)=\int_{0}^{y} \lambda(t) d t
$$

In accordance with Robinson's conjecture, the inverse dependence of the $\sigma_{k}$ upon personal income $y_{k}$ is approximated by the relation

$$
\sigma_{k}=1+a y_{k}^{-b}
$$

where $a$ and $b$ are positive coefficients.

\subsection{Income Inequality and the Market Outcomes}

Figure 1 depicts how the equilibrium mark-ups change when the income inequality in the economy increases. In contrast to the Dixit-Stiglitz case, where mark-ups are constants, it shows that mark-ups may vary due to transformation of income distribution and may ambiguously depend upon the degree of inequality.

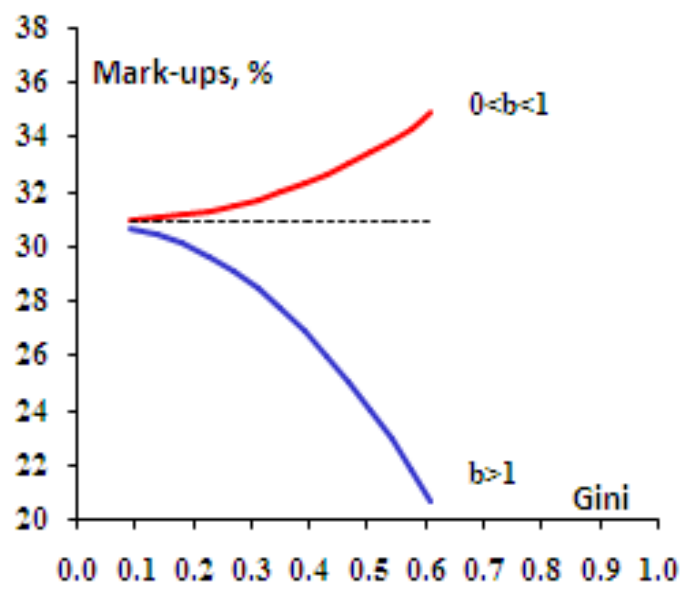

Figure 1. The mark-ups as a function of income inequality

Red line in Fig.1 corresponds to positive $b$ coefficient being less than unity, while the blue line corresponds to $b$ greater than unity. To explain the mark-ups behavior, it's

\footnotetext{
1 Interchanging the discreet distribution by continuous one is done exclusively due to analytical convenience and does not distort the main results of the paper.
} 
useful to calculate the market demand elasticity coefficient. It turns out to be the same across all varieties and up to the sign equals the "effective" parameter sigma:

$$
\begin{gathered}
\widetilde{\varepsilon}_{i}=-\widetilde{\sigma} \\
i=1,2, \ldots, N .
\end{gathered}
$$

Usage of the mean-preserving spread of the income distribution means that for some groups of consumers their income is becoming lower (and so these consumers are getting poorer) while for another groups, on the contrary, their income is becoming higher (thereby making these consumers relatively richer). Income group's contribution into market demand pattern and market demand elasticity coefficient (17) strongly depends upon the value of the coefficient $b$ in (16).

For $b$ less than unity, the groups becoming richer contribute more than those becoming poorer, thereby providing decrease in the "effective" parameter sigma and, hence, in the elasticity of the market demand, making it less elastic. As a consequence, in accordance with (9), it enables firms to charge higher mark-ups.

On the contrary, for $b$ greater than unity, the groups becoming richer contribute less than those becoming poorer, making demand curve more elastic and thereby providing decrease in the value of the mark-ups. Asymmetry in the mark-ups behavior (the rate of mark-ups decrease being higher than the rate of mark-ups increase) points out that effects of consumers' impoverishment exert greater influence on mark-ups deviation, compared to effects of consumers' enrichment.

They demonstrate that increases in the prices and mark-ups are accompanied by the decrease of firm size and increase in the number of firms. On the contrary, the decrease in the prices and mark-ups induces an opposite effect on firm size and number of firms.

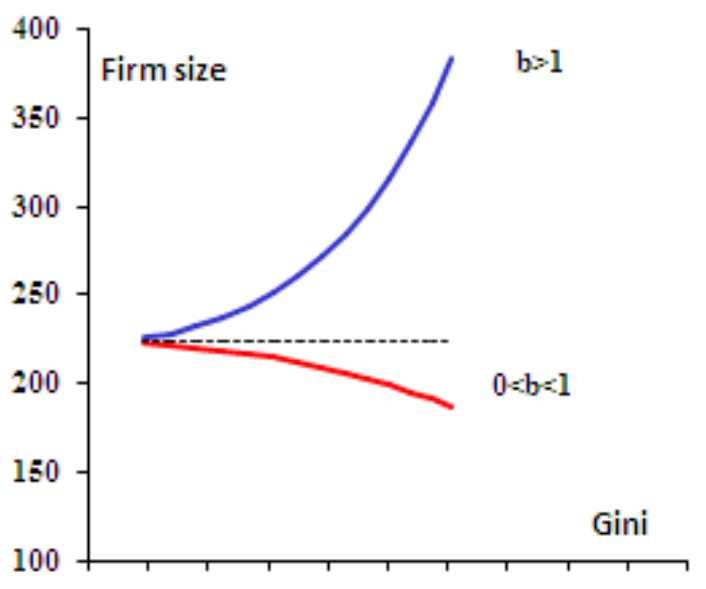

$\begin{array}{lllllllllll}0.0 & 0.1 & 0.2 & 0.3 & 0.4 & 0.5 & 0.6 & 0.7 & 0.8 & 0.9 & 1.0\end{array}$

Figure 2. Firm size as a function of income inequality

In Fig. 2 and Fig. 3 the equilibrium firm size and number of firms are represented as functions of income inequality.

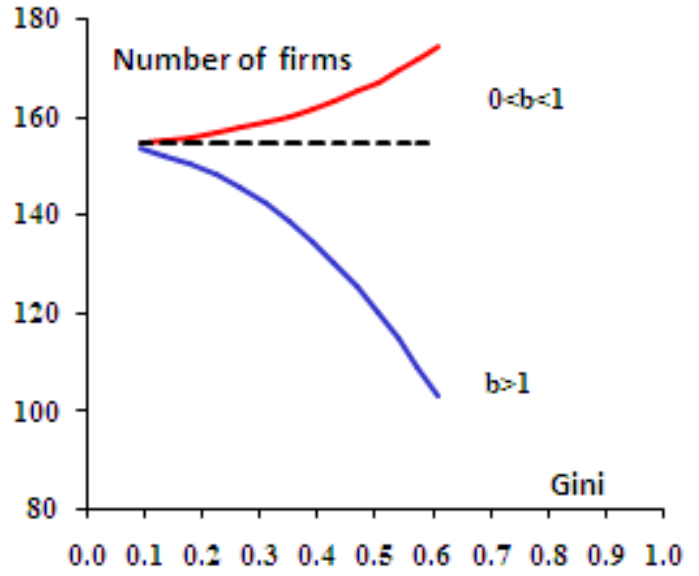

Figure 3. Number of firms as a function of income inequality

\section{Discussion}

To understand the findings, represented in the previous section, note that the same income distribution induces different $\sigma_{k}$ distributions for $0<b<1$ and $b>1$. As a consequence, the same income inequality differently influences the value of the "effective" parameter sigma and intensity of competition. Income inequality increase for $0<b<1$ reduces the value of the "effective" parameter sigma. This fact enables firms to produce more diversified varieties, thereby reducing intensity of market competition. As a consequence, existing firms raise their mark-ups and enjoy positive profit. This observation attracts new firms on the market. Firm's number increases with their size becoming smaller.

On the contrary, the case $b>1$ corresponds to the increase in the value of the "effective" parameter sigma. In such a case firms produce less diversified varieties and intensify the market competition. As a consequence, existing firms obtain negative profit and reduce their mark-ups. Some firms escape the market. The number of firms decreases with their size becoming larger.

The results of the model demonstrate that income inequality strongly impacts the degree of product differentiation and other parameters of the market through its effect on the elasticity of consumers' demand and toughness of monopolistic competition. This impact, though, has ambiguous character and depends upon the shape of the function $\sigma_{k}=\sigma\left(y_{k}\right)$. If function $\sigma_{k}=\sigma\left(y_{k}\right)$ has rather flat dependence upon income $(0<b<1)$, than groups with higher incomes have greater impact on market demand elasticity, than poorer ones. Market demand elasticity, becoming less elastic, enables firms to charge higher prices and set higher mark-ups. In the opposite case of the steep $\sigma_{k}$ dependence on the income $(b>1)$ the contribution of poorer groups prevails. In this case market demand elasticity, becoming more elastic, forces firms to reduce their prices and set lower mark-ups. 


\section{Conclusion}

The paper develops the model of monopolistic competition with heterogeneous consumers by using the modified CES utility function depending on consumer's personal income. The proposed approach makes it possible to dispense with the identity of consumer's preferences in formation of an aggregate demand and takes into account the difference between the individual and collective behavior of consumers.

The model allows one to investigate the income inequality impact upon market outcomes. In contrast to the commonly used CES preferences, which do not capture the effects of consumer income distribution and intensity of competition on market structure, the present model captures both of these effects. In contrast to the traditional models it shows that market structure (i.e. the equilibrium prices and mark-ups, firm size and number of firms) can ambiguously depend upon income inequality.

All results obtained in the present paper refer to the partial equilibrium case, since income distribution of the consumers is given exogenously. To get the general equilibrium version of the model one has to take into account determinants of income inequality and consider how wage rates vary across workers with different skills and abilities. This could be done by using results of theoretical and empirical findings, presented in [18].

The outlined model can also be easily extended to investigate the trade effects in the open economy case. The analysis could be carried out both on the basis of symmetric equilibrium with identical firms and in more general setting, where firms are supposed to differ in their marginal costs.

\section{REFERENCES}

[1] A. K. Dixit, J .E. Stiglitz. Monopolistic competition and optimum product diversity, American Economic Review, Vol.67, 297-308, 1977.

[2] P. R. Krugman. Increasing returns, monopolistic competition, and international trade, Journal of International Economics, No. 9, 151-175, 1979.

[3] Brakman, B. J. Heijdra. The monopolistic Competition in Retrospect, Cambridge University Press, Cambridge, 2004.
[4] A. P. Kirman. Whom or What Does the Representative Agent Represent? The Journal of Economic Perspectives, Vol.6, No.2, 117-136, 1992.

[5] J.E. Hartley. The Origins of the Representative Agent, JoB. J. Heijdra. The Journal of Economic Perspectives, Vol. 10, No.2, 169-177, 1996.

[6] J. R. Markusen. Putting per-capita income back into trade theory, NBER Working paper No. 15903, 2010.

[7] C. Benassi, A. Chirko, R. Cellini. Personal Income Distribution and Market Structure, German Economic Review, Vol.3, No.3, 327-338, 2002.

[8] C. Benassi, A. Chirko, C. Colombo. A Model of Monopolistic Competition with Personal Income Distribution, Metroeconomica, Vol.56, No.3, 305-317, 2005.

[9] Y. C. Choi, D. Hummels, C. Xiang. Explaining Import Quality: The Role of Income Distribution, Journal of International Economics, 77, 265-275, 2009.

[10] M. Dalgin, V. Trindade, D. Mitra. Inequality, Non-homothetic Preferences and Trade: A Gravity Approach, Southern Economic Journal, 74, 747-774, 2008.

[11] A. C. Fieler. Non-homotheticity and bilateral trade: evidence and a quantitative explanation, Econometrica, Vol. 79, No. 4, 1069-1101.

[12] I. Simonovska. Income Differences and Prices of Tradables, NBER Working paper No. 16233, 2010.

[13] A. Tarasov. Consumer Preferences in Monopolistic Competition Models, MPRA Working paper No. 19990, 2010 .

[14] P. P. Combes, T. Mayer, J.-F. Thisse. Economic Geography. The Integration of Regions and Nations, Princeton University Press, 2008.

[15] J. V. Robinson. The Economics of Imperfect Competition, 1933.

[16] A. V. Yurko. How does income inequality affect market outcomes in vertically differentiated markets? International Journal of Industrial Organization, Vol. 29, 493-503, 2011.

[17] P. Lukasiewicza, K. Karpio, A. Orlowski. The models of personal incomes in USA, Acta Physica Polonica A, Vol. 121, No. 2-B, 82-85, 2010.

[18] E. Helpman, O. Itskhoki, M.-A. Muendler, S. Redding. Trade and Inequality: From Theory to Estimation, CEP Discussion Paper No.1138, 2012. 